\title{
Assessment of the physical and mechanical properties of plaster of Paris bandage cast used as a splinting and casting materials
}

\author{
A. J. Parmar ${ }^{1}$, S.K.Tyagi², V. S. Dabas ${ }^{3}$, J. N. Mistry², S. K. Jhala ${ }^{1}$, D. N. Suthar ${ }^{1}$, R. H. Bhatt ${ }^{1}$, D. V. Pansuria ${ }^{1}$ and \\ I. M. Bhatti ${ }^{1}$
}

1. Department of Veterinary Surgery and Radiology, Vanbandhu College of Veterinary Science and Animal Husbandry, Navsari Agricultural University, Vijalpore, Gujarat, India; 2. Department of Teaching Veterinary Clinical Complex, Vanbandhu College of Veterinary Science and Animal Husbandry, Navsari Agricultural University, Vijalpore, Gujarat, India; 3. Department of Animal Science, Navinchandra Mafatlal College of Agriculture, Navsari Agricultural University, Navsari, Gujarat, India.

Corresponding author: S. K. Tyagi, e-mail: surbhiivri@gmail.com, AJP: parmarajit1341@gmail.com, VSD: vsdabas@yahoo.co.in, JNM: jnmistrynau@gmail.com, SKJ: drshivrajjhala@gmail.com, DNS: drdipaksuthar@yahoo. co.in, RHB: drrhbhatt@yahoo.com, DVP: dhaval.pansuria@gmail.com, IMB: iqbalbhatti2@gmail.com

Received: 26-07-2014, Revised: 18-10-2014, Accepted: 12-11-2014 Published online: 23-12-2014

doi: 10.14202/vetworld.2014.1123-1126. How to cite this article: Parmar AJ, Tyagi SK, Dabas VS, Mistry JN, Jhala SK, Suthar DN, Bhatt RH, Pansuria DV, Bhatti IM (2014) Assessment of the physical and mechanical properties of plaster of Paris bandage cast used as a splinting and casting materials, Veterinary World 7(12): 1123-1126.

\begin{abstract}
Aim: To assess the physical and mechanical properties of plaster of Paris (POP) bandage cast used as a splinting and casting materials.

Materials and Methods: POP casts were divided into three Groups A, B and C with 2, 3 and 8 layer for POP bandage, respectively ( $\mathrm{n}=6$ in each group). Handling characters, technical easiness or difficulties, setting time, weight, diameter and thickness of the casts were recorded for different groups. The casts were mounted on universal testing machine and axial load was applied @ $10 \mathrm{~mm} / \mathrm{min}$ until failure. The load deflection graphs were plotted. The maximum force at which failure of the casts occurred was recorded. Stress, strain, modulus of elasticity (MOE) and stiffness of casts were calculated.
\end{abstract}

Result: Construction of POP bandage cast was messy and required 45-60 min for hardening. 8 layer POP cast was comparatively heavier in weight and thicker in cross section than 3 layer cast followed by 2 layer cast. Under axial compression, the load bearing capacity of 8 layer POP casts was more than 2 and 3 layer cast.

Conclusion: The values of load bearing capacity, stress, stiffness and MOE of cast were the highest for 8 layer POP cast followed by 2 and 3 layer cast. Use if splints with POP cast is recommended due to its poor mechanical properties.

Keywords: axial load, cast, compression, physical properties, plaster of Paris bandage.

\section{I ntroduction}

An orthosis is a custom-made or prefabricated device applied to a segment to stabilize, protect, promote healing, prevent or correct deformity or assist function that includes casts and splints [1]. Historically, plaster of Paris (POP) have been the most commonly available material used both for immobilization of acute lesions or mobilization splinting. It is called POP because it was first prepared from the gypsum (calcium sulfate dehydrate) mined in Paris, France. Gypsum plaster or the POP, is produced by heating gypsum to about $300^{\circ} \mathrm{F}\left(150^{\circ} \mathrm{C}\right)$. When the dry plaster powder is mixed with water, it re-forms into gypsum. The setting of unmodified plaster starts about 10 min after mixing and is complete in about $45 \mathrm{~min}$; but not fully set for $72 \mathrm{~h} \mathrm{[2].}$

The casting material can be POP and synthetic casting materials like fiberglass or polypropylene substrate impregnated with water activated polyurethane resin [3]. POP has been used with aluminum and bamboo splints to manage the closed fractures below the

Copyright: The authors. This article is an open access article licensed under the terms of the Creative Commons Attributin License (http:// creative commons.org/licenses/by/2.0) which permits unrestricted use, distribution and reproduction in any medium, provided the work is properly cited. stifle and elbow joints in case of large animals [4,5]. Complications of POP include muscle atrophy, hoof exposure, rope gall, and pressure point bites [6]. The disadvantages of POP include long setting times, messy application, its poor mechanical and radiographic properties and high water permeability $[7,8]$. Still POP casting is one of the most widely used methods of external fixation in veterinary practice because of its easy availability and low cost as compared to synthetic fiberglass bandages.

However, the incidence of breaks of POP splints is a concerning matter [8]. Therefore, knowledge of the materials properties and handling techniques is of great importance when constructing orthoses and prostheses [9].

Thus, the purpose of this study was to evaluate the physical and mechanical properties of specimens constructed with POP bandages for use in orthopedic casts and splints.

\section{Material and Methods}

Preparation of the sample cast

Totally, 18 sample casts $(10 \mathrm{~cm}$ length $)$ made of POP bandage (Fixplast Wilson Tapes Pvt. Ltd. Mehsana, Gujarat) were divided into three Groups A, $\mathrm{B}$ and $\mathrm{C}$ with 2, 3 and 8 layers of POP bandage, 
respectively ( $\mathrm{n}=6$ in each group). POP bandage was soaked in lukewarm water till bubbles come out and then squeezed gently, after which it was wrapped around the polyvinyl chloride (PVC) pipe of $25 \mathrm{~mm}$ diameter and external surface smoothed to prevent crack (Figure-1). The cast prepared was then allowed to dry and harden. After application of all casts, each cast was allowed to dry for $24 \mathrm{~h}$ before the PVC pipe former was removed (Figure-2). Then an additional $48 \mathrm{~h}$ was allowed for full drying before mechanical testing.

The weight of each casts was taken with digital weighing machine. The outer diameter and thickness of each cast sample was measured at different locations with digital vernier calipers and then the averaged values were determining the given cast's outer diameter and thickness. The location of the measurement site at each end of the cast was selected at random. Additionally, basic aspects were controlled to guarantee the standardization like construction of all specimens by a single operator.

\section{Biomechanical testing}

Sample casts were mounted on universal testing machine (UTM - Autograph AG-100 KNG), and axial load was applied @ $10 \mathrm{~mm} / \mathrm{min}$ until failure (Figure-3). The load deflection graphs were plotted. The maximum force at which failure of the casts occurred was recorded. In addition, stress $\left(\mathrm{N} / \mathrm{mm}^{2}\right)$, strain, stiffness $(\mathrm{N} / \mathrm{mm})$ and modulus of elasticity $(\mathrm{MOE})\left(\mathrm{N} / \mathrm{mm}^{2}\right)$ of casts were calculated [10].

\section{Statistical analysis}

Data obtained were analyzed using ANOVA, and mean differences were tested for statistical significance by Duncan's multiple range test using software (Statistical Package for Social Sciences version 15.0, IBM, US). Significance was recorded at $\mathrm{p}<0.05$.

\section{Results}

Construction of POP bandage cast was easy with good molding properties but was a little messy. Mean \pm SE of hardening or setting time was $48.64 \pm 0.98 \mathrm{~min}$.

Physical parameters (weight, diameter and thickness) and mechanical parameters (load, stress, strain, stiffness, MOE) of POP casts increased with the increase in number of layers of bandage $(8>3>2)$. Inner diameter of the casts was kept constant as $25 \mathrm{~mm}$ for all the samples. The weight, outer diameter and thickness of 8 layer POP cast was significantly $(p<0.05)$ higher than 3 layer and 2 layer cast (Table-1).

The mean \pm standard error (SE) value of maximum load taken by 8 layer POP cast was $366.67 \pm 26.35$ $\mathrm{N}(\approx 36.67 \mathrm{~kg})$, was significantly $(\mathrm{p}<0.05)$ higher than 3 layer $(58.33 \pm 4.17 \mathrm{~N}, \approx 5.83 \mathrm{~kg})$ and 2 layer POP cast $(29.17 \pm 2.63 \mathrm{~N}, \approx 2.91 \mathrm{~kg})$. However, there was no significant $(p>0.05)$ difference was observed in load, stress, strain and stiffness between 2 layer and 3 layer POP casts. The mean \pm SE value of stress

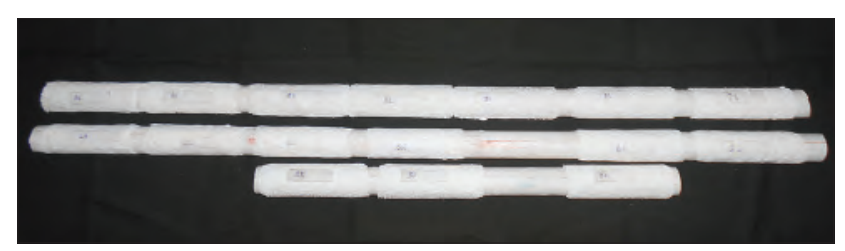

Figure-1: Construction of plaster of Paris cast on polyvinyl chloride mold.

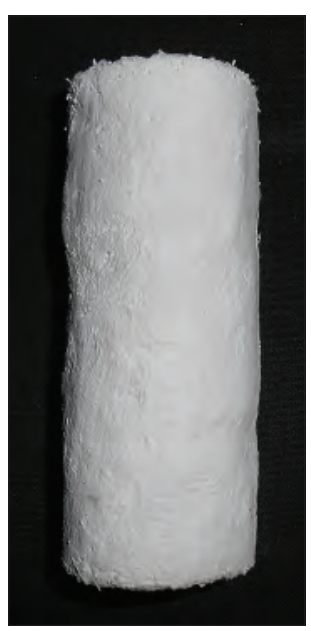

Figure-2: Plaster of Paris bandage cast.

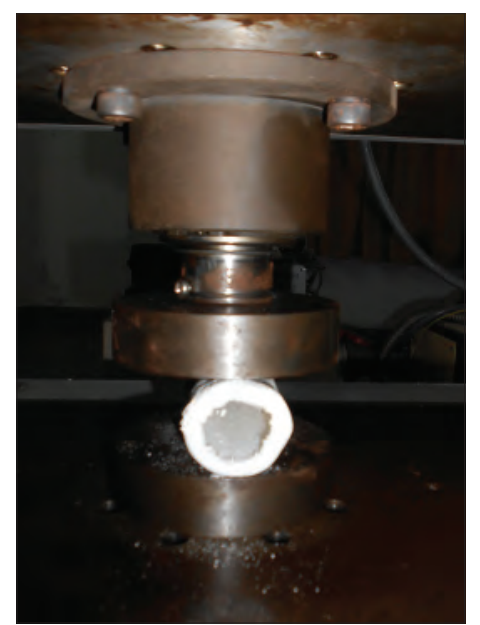

Figure-3: Compression testing performed on plaster of Paris cast.

strain and stiffness recorded for 8 layer POP cast was significantly $(p<0.05)$ higher than 3 layer followed by 2 layer POP casts. However, MOE showed no significant ( $p>0.05)$ difference between three sub-groups of POP sample casts (Table-1).

\section{Discussion}

Casts can be a very effective, rigid form of fixation when applied properly. Casts are defined as the orthotics that is made of POP or other fiberglass bandages and cannot be removed from the patient [11]. It is extremely important to remember that the cast and splint must immobilize both the joint above and below the fracture. They are ideal for closed fractures located below the elbow or stifle [3]. POP casting is one of the oldest methods of fracture fixation and the 
Table-1: Mean \pm SE values of physical and mechanical parameters of different layer of POP casts.

\begin{tabular}{lccc}
\hline Parameter & Group A (2 layer) & Group B (3 layer) & Group C (8 layer) \\
\hline Weight (gram) & $9.16 \pm 0.60^{\mathrm{a}}$ & $17.83 \pm 1.14^{\mathrm{b}}$ & $51.33 \pm 2.61^{\mathrm{c}}$ \\
Outer diameter (mm) & $29.49 \pm 0.52^{\mathrm{a}}$ & $31.35 \pm 0.25^{\mathrm{b}}$ & $37.73 \pm 0.63^{\mathrm{c}}$ \\
Thickness (mm) & $1.68 \pm 0.23^{\mathrm{a}}$ & $2.56 \pm 0.13^{\mathrm{b}}$ & $6.21 \pm 0.26^{\mathrm{c}}$ \\
Maximum load (N) & $29.17 \pm 2.63^{\mathrm{a}}$ & $58.33 \pm 4.17^{\mathrm{a}}$ & $366.67 \pm 26.35^{\mathrm{b}}$ \\
Stress (N/mm $)$ & $0.10 \pm 0.01^{\mathrm{a}}$ & $0.12 \pm 0.00^{\mathrm{a}}$ & $0.29 \pm 0.02^{\mathrm{b}}$ \\
Strain $(\%)$ & $45.15 \pm 7.36^{\mathrm{a}}$ & $59.46 \pm 9.30^{\mathrm{a}}$ & $120.08 \pm 5.60^{\mathrm{b}}$ \\
Stiffness (N/mm) & $1.17 \pm 0.14^{\mathrm{a}}$ & $2.27 \pm 0.29^{\mathrm{a}}$ & $12.72 \pm 1.10^{\mathrm{b}}$ \\
MOE (N/mm $)$ & $0.0024 \pm 0.0004$ & $0.002 \pm 0.0001$ & $0.0025 \pm 0.0002$ \\
\hline
\end{tabular}

Means with different superscripts in the same row differ significantly

universal acceptance of POP as a casting material is largely owing to its low cost and ease of molding.

In the present study, we prepared 2, 3 and 8 layer sample casts of POP bandages. In order to minimize the variation, the length of all sample cast was kept $10 \mathrm{~cm}$, and an inner diameter was kept constant as $25 \mathrm{~mm}$, similar to the earlier studies [11-13]. 8 layer sample casts were prepared for standardization of procedure for both sampling and biomechanical study as described in an earlier study [11]. Nevertheless, in clinical situations we are using either two or three layer POP casts. Thus, we prepared two and three layers of sample casts for biomechanical testing as well. In an earlier study, POP bandage was tested for its mechanical properties by making cast samples of $3,6,8,10$, 12 and 14 layer of POP bandage. They suggested that the use of 10 layers of POP yields a better relationship between material's weight and final strength [12].

Handling of POP bandage cast was easy with good casting properties. Application of POP cast was messy and cumbersome. Similar findings were also reported in earlier studies [14]. In addition, hardening time for the POP cast was $48.64 \pm 0.98 \mathrm{~min}$. Earlier clinical studies reported the hardening time of POP casts as 15-20 and 20-25 [6,15]. The higher value of the hardening time of POP casts in the present study may be due to the higher humidity in this area, which might have led to delay in drying of the cast, in addition to the different brand of the cast material used.

For all the three sub-groups, 8 layer POP cast was heavier and thicker than 3 layer followed by 2 layer cast. An increase in weight corresponding with a number of layers is also reported in an earlier study [12].

Compression testing was done on POP casts after mounting them on UTM, and an axial load was applied @ $10 \mathrm{~mm} / \mathrm{min}$ until failure [11-13].

In the present study, the load taken by 8 layer POP cast was 6.28 times higher than 3 layer cast. Also, there was an approximately, 2 fold increase in load taken by 3 layer POP cast as compared to 2 layer cast. In an earlier study different brand of 8 layer POP casts were compared, wherein, maximum load taken for different brands came as $612.85 \pm 58.61 \mathrm{~N}$ for A brand, $482.80 \pm 60.54 \mathrm{~N}$ for brand $\mathrm{B}$ and $516.84 \pm 32.04 \mathrm{~N}$ for brand $C$ [11]. The difference in the values of the load in the two studies may be due to the different brands of cast material used. In addition, the experimental conditions are also different for different studies that also add to the variation in the results and the results cannot be directly compared.

The mean \pm SE values of stress, stiffness and MOE were also higher for 8 layer POP cast as compared to 3 layers followed by 2 layer cast. In the present study, maximum load taken by the 2, 3 and 8 layer POP casts were nearly about $2.91 \mathrm{~kg}, 5.83 \mathrm{~kg}$ and $36.67 \mathrm{~kg}$, respectively. Consequently, in the clinical situations, the use of splints along with POP bandage casts is highly recommended, as the inherent strength of the POP casts is very low. However, for more load, addition of more layers of POP bandage is required, which adds to the bulk and weight of the casts.

\section{Conclusion}

To conclude, preparation of POP cast is messy and required more time for hardening. As the number of layers increases, the values of load bearing capacity, stress, stiffness and MOE of cast increases. But the addition of layers also adds to the weight and bulk of the cast and hence use of splints with POP cast is recommended.

\section{Authors' Contributions}

AJP and SKT designed the study. SKJ, DNS and RHB helped in recording of the data and collection of literature. DVP and IMB contributed in sample preparation. VSD and JNM drafted and corrected the manuscript. All authors read and approved the final manuscript.

\section{Acknowledgments}

The authors are thankful to the Principal and Dean, Vanbandhu College of Veterinary Science and Animal Husbandry, NAU, Navsari to provide necessary funds for this study.

\section{Competing I nterests}

The authors declare that they have no competing interests.

\section{References}

1. Gravlee, J.R. and Van Durme, D.J. (2007) Braces and splints for musculoskeletal conditions. Am. Fam. Physician, 75(3): 342-8.

2. Colditz, J.C. (2002) Plaster of Paris: Forgotten hand splinting materials. J. Hand Ther., 15(2): 144-157.

3. Johnson, A.L. (2013) Fundamentals of orthopedic surgery 
and fracture management. In: Fossum, T.W., editor. Small Animal Surgery. $4^{\text {th }}$ ed. Mosby Elsevier, Philadelphia. p1033-1105.

4. Anderson, D.E., St-Jean, G., Vestweber, J.G. and Desrochers, A. (1994) Use of Thomas splint-cast combination for stabilization of tibial fractures in cattle: 21 cases (1973-1993). Agric. Pract., 15: 16-23.

5. Kushwaha, R.B., Gupta, A.K., Bhadwal, M.S., Kumar, S. and Tripathi, A.K. (2011) Incidence of fractures and their management in animals: A clinical study of 77 cases. Indian J. Vet. Surg., 32(1): 54-56.

6. Singh, V., Dudi, P.R. and Gahlot, T.K. (2010) Comparative efficacy of plaster of Paris and fibre glass casts for repair of long bone fractures in goats. Indian Vet. J. 31(2): 135-136.

7. Berman, A.T. and Parks, G.P. (1990) A comparison of the mechanical properties of fiberglass cast materials and their clinical relevance. J. Orthop. Trauma., 4: 5-92.

8. Wytch, R., Ashcroft, G.P., Ledingham, W.M., Wardlaw, D. and Ritchie, I.K. (1991) Modern splinting bandages. J. Bone Joint Surg., 73(1):88-91.

9. Kogler, G.F. (2000) Materials and technology. In: Orthotics and Prosthetics in Rehabilitation. Butterworth-Heinemann, Boston.
10. Gupta, S.K. (2009) Properties of bulk matter. In: Modern's ABC of Physics. $15^{\text {th }}$ ed. In: Gupta, S.K. and Gupta, A., editors. Modern Publishers, India. p647-849.

11. Vieira, G.C., Fonseca, M.D.C.R., Shimano, A.C., Mazzer, N., Barbieri, C.H. and Elui, V.C.M. (2006) Evolution of the mechanical properties of plaster bandages used for orthoses manufacture, marketed by three different manufacturers. Acta. Orthop. Bras., 14 (3):122-125.

12. Vieira, G.C., Barbosa, R.I., Marcolino, A.M., Shimano, A.C., Elui, V.M.C. and Fonseca, M.C.R. (2011) Influence of the number of layers of paris bandage plasters on the mechanical properties speciments used on orthopedic splints. Rev. Bras. Fisioter, 15(5): 380-385.

13. Charles, M.N. and Yen, D. (2000) Property of a hybrid plaster-fibreglass cast. Can. J. Surg., 43(5): 365-367.

14. Wytch, R., Mitchell, C.B., Wardlaw, D., Ledingham, W.M. and Ritchie, I.K. (1987) Mechanical assessment of polyurethane impregnated fibreglass bandage for splinting. Prosthet. Orthot. Int., 11: 128-134.

15. Avasthi, H.A., Patel, P.B., Patel, J.B., Patel, T.P. and Gami, M.S. (2012) Comparative effectiveness of plaster of paris and fibre glass casts in the management of long bone fractures in caprines. Intas Polivet, 13(II): 371-373.

$* * * * * * * *$ 